\title{
Echocardiography in the evaluation of the cyanotic newborn infant
}

\author{
Michael J. Godman, Poolin Tham, and B. S. Langford Kidd \\ From the Department of Cardiology, Hospital for Sick Children, Toronto, Ontario, Canada
}

Echocardiographic studies were performed in 45 sick newborn infants with cyanotic congenital heart disease, in 6 newborn infants with cyanosis of non-cardiac origin, and in 50 normal newborn infants without heart disease. No false positive diagnosis was made in 12 cases of the hypoplastic left heart syndrome identified by a small left ventricular dimension (o-II mm), hypoplastic or atretric mitral valves, and hypoplastic or atretic aortic roots $(0-7 \mathrm{~mm})$. Pulmonary atresia with intact ventricular septum - 5 cases - was identified by a small right ventricular dimension (0-6 mm), and a hypoplastic tricuspid valve and tricuspid atresia 2 cases - by a small right ventricular dimension $(0-3 \mathrm{~mm})$ with an absent tricuspid valve. $A$ strip chart facility which allowed the presentation of several areas of cardiac interest within the one recording had distinct advantages over polaroid films in the recognition of discontinuity of the interventricular septum with the aorta, which was the hallmark of tetralogy of Fallot, and in determining the abnormal spatial relations between the great vessels in cases of D-transposition of the great arteries.

Echocardiography is a safe and accurate method of diagnosis of congenital heart disease in the newborn and adds considerably to the evaluation before cardiac catheterizaion.

Echocardiography is an established, safe, and noninvasive technique used in the diagnosis and assessment of many cardiac disorders in adults. It is only recently, however, that the potential of this method has been examined in assessing congenital heart disease and there have been few studies in the newborn infant (Lundström and Edler, I97I; Chesler et al., 1971; Meyer and Kaplan, 1972).

Since many cardiac echoes are fleeting and require a critical transducer position, a continuous echogram greatly enhances the chances of capturing them. The use of a strip chart recorder enables a continuous recording to be obtained while the transducer is being moved; this has greatly facilitated the identification of abnormal cardiac anatomy (Feigenbaum, 1972). Since this method allows the echocardiographic presentation of several areas of cardiac interest within one trace, it should be ideally suited to the study of congenital heart disease and, in particular, of those cases in which the normal cardiac relations are altered.

The purpose of this study was to determine the role of echocardiography in assessing the sick newborn infant with cyanosis and to evaluate the usefulness and limitations of the technique in diagnosing

Received II September 1973. specific cyanotic congenital heart lesions in the neonate.

\section{Subjects and methods}

Echocardiograms were recorded in three groups of patients.

Group I consisted of 50 newborn infants thought to be normal on physical examination. Their ages ranged from 6 hours to 4 weeks and their weights from $\mathrm{I} \cdot 9$ to $4.3 \mathrm{~kg}$. These infants served as a control for those with cyanotic congenital heart disease.

Group 2 was composed of 45 newborn infants with proven cyanotic congenital heart disease. Their ages at the time of examination ranged from 3 hours to 4 weeks. In each case the echocardiographic findings were correlated with cardiac catheterization and angiographic results or necropsy findings. Table $\mathbf{I}$ shows the number of infants in each diagnostic category.

Group 3 consisted of 6 infants who presented with cyanosis shortly after birth and were initially suspected of having cyanotic congenital heart disease. The subsequent course, in each case, however, disclosed a noncardiac cause for the cyanosis.

Echocardiograms were performed using a SmithKline Ekoline 20A Ultrasonoscope and a 2.25 mega Hz transducer with a face diameter of $1 \cdot 6 \mathrm{~cm}$. During the early part of the study echocardiograms were recorded only on polaroid film. In the majority of cases, however, 
TABLE I Diagnosis in 45 newborn infants with cyanotic congenital heart disease

\begin{tabular}{ll}
\hline Diagnosis & No. of patients \\
\hline Hypoplastic left heart syndrome & 12 \\
Pulmonary atresia with intact ventricular & \\
septum & 5 \\
Tricuspid atresia & 2 \\
D-transposition of great arteries & I0 \\
Tetralogy of Fallot & 9 \\
Total anomalous pulmonary venous drainage & 2 \\
Miscellaneous & 5 \\
\hline Total & 45 \\
\hline
\end{tabular}

recordings were also obtained on a strip chart from an Electronics for Medicine DR 8 recorder interfaced with the Ekoline 20A Ultrasonoscope.

All the infants were examined in the supine position without sedation. A water soluble gel was used to produce airless contact between the transducer and skin.

The controls of the ultrasonoscope were set so that the depth compensation was not in use. The reject control was set at 2 to 3 and the damping control was minimized. The near and coarse gain controls were adjusted during the course of the examination to produce a strong echo of the structure being examined. In each case a standardized technique based on that described by Feigenbaum (1972) and Solinger, Elbl, and Minhas (1973) was used to obtain as complete an ultrasonic evaluation of the heart and great vessels as possible.

The characteristic echo of the anterior leaflet of the mitral valve was first located by positioning the transducer at the third or fourth intercostal space and directing the beam posteriorly. Then, by rotating the transducer slightly inferolaterally and adjusting, if necessary, the near and coarse gain controls, echoes from the right ventricular cavity, interventricular septum, and left ventricular posterior wall were identified (Fig. I). The right ventricular dimension was measured as the distance between the right ventricular endocardial echoes and those from the right side of the interventricular septum at end-diastole. The left ventricular dimension was measured as the distance between left-sided septal echoes and the left ventricular posterior wall endocardial echoes at end-diastole. Rotation of the transducer medially and slightly inferiorly identified tricuspid valve movement (Fig. 2). Measurement of the maximum excursion of the mitral and tricuspid valves was taken as the distance between their most anterior or open position and their most posterior or closed position.

Echoes from the aortic root and aortic valve cusps were obtained by locating the mitral valve echo and rotating the transducer medially and superiorly until two parallel signals moving anteriorly during systole and posteriorly during diastole were obtained (Fig. 3). Normally, the mitral valve echo merges into the echo of the posterior aortic wall and the echoes from the interventricular septum merge with those of the anterior wall (Fig. 4). This procedure identifies aortic and ventricular septal

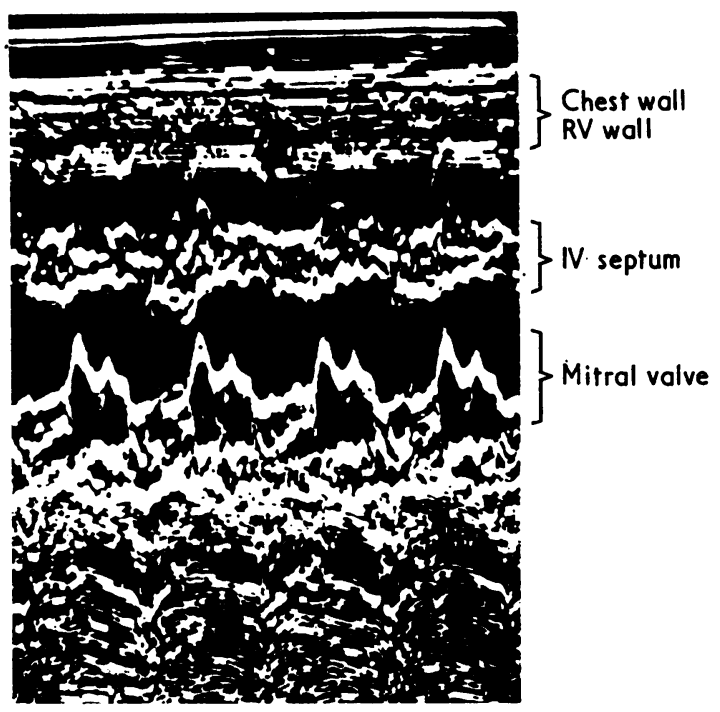

FIG. I Echocardiogram of normal newborn infant showing mitral valve and the interventricular (IV) septum.

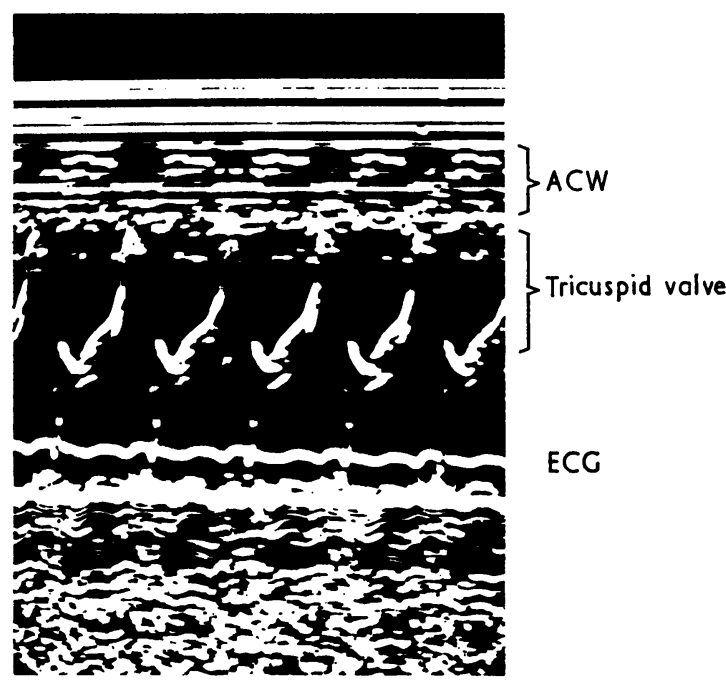

FIG. 2 Echocardiogram of tricuspid valve in normal newborn.

continuity and mitral valve and aortic valve continuity. Measurement of the aortic root diameter was made at end-systole between the outside echoes of the aorta. The anteroposterior diameter of the left atrial cavity was assessed by measuring at end-systole between the posterior wall of the aortic root and the left atrial endocardial surface.

The pulmonary artery was located by moving the transducer slightly cephalad from the position in which the aortic valve was recorded and directing the ultrasound beam slightly laterally and superiorly until an 


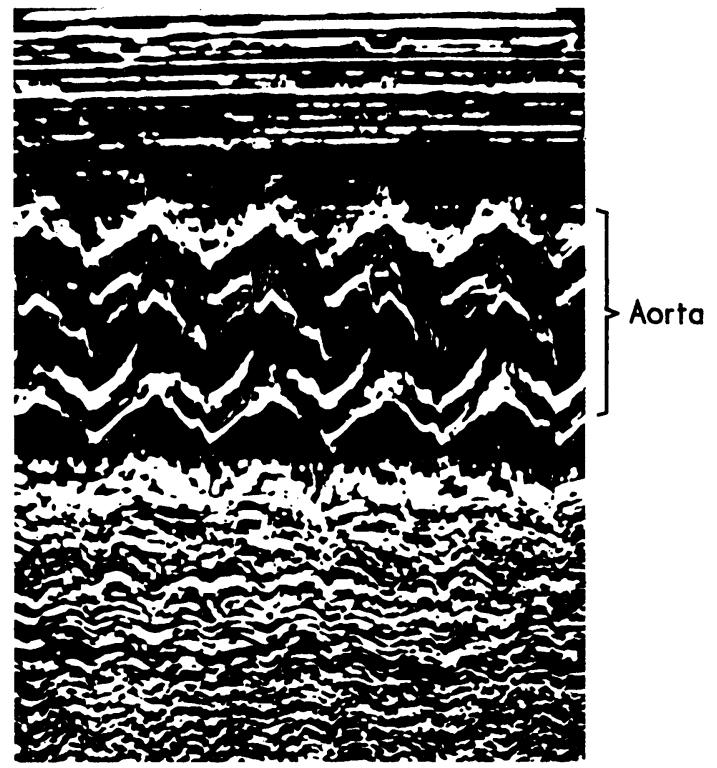

FIG. 3 Echocardiogram of aortic root and aortic valve cusps in normal newborn infant. echo-free space lying superficially just beneath the anterior chest wall was seen. Echoes from the pulmonary valve cusps could then usually be identified within this space (Fig. 5). In some cases, the pulmonary valve was also located by recording directly over the second left interspace.

\section{Normal}

\section{Results}

Mitral and tricuspid valve echoes were recorded in all 50 normal newborn infants; aortic echoes in 48 of the 50 and pulmonary valve echoes in $4 \mathrm{I}$ of the 50. In 12 cases, though pulmonary valve cusp echoes were identified, clear resolution of the anterior wall of the pulmonary artery from the anterior chest wall could not be obtained and no reliable measure of the anteroposterior diameter of the pulmonary artery could be made. The values for the left ventricular dimensions are from measurements in 36 of the infants, for in 14 a technically unsatisfactory recording did not permit identification of the endocardial surface of the posterior left ventricular wall from posterior chordal structures. Table 2 gives the

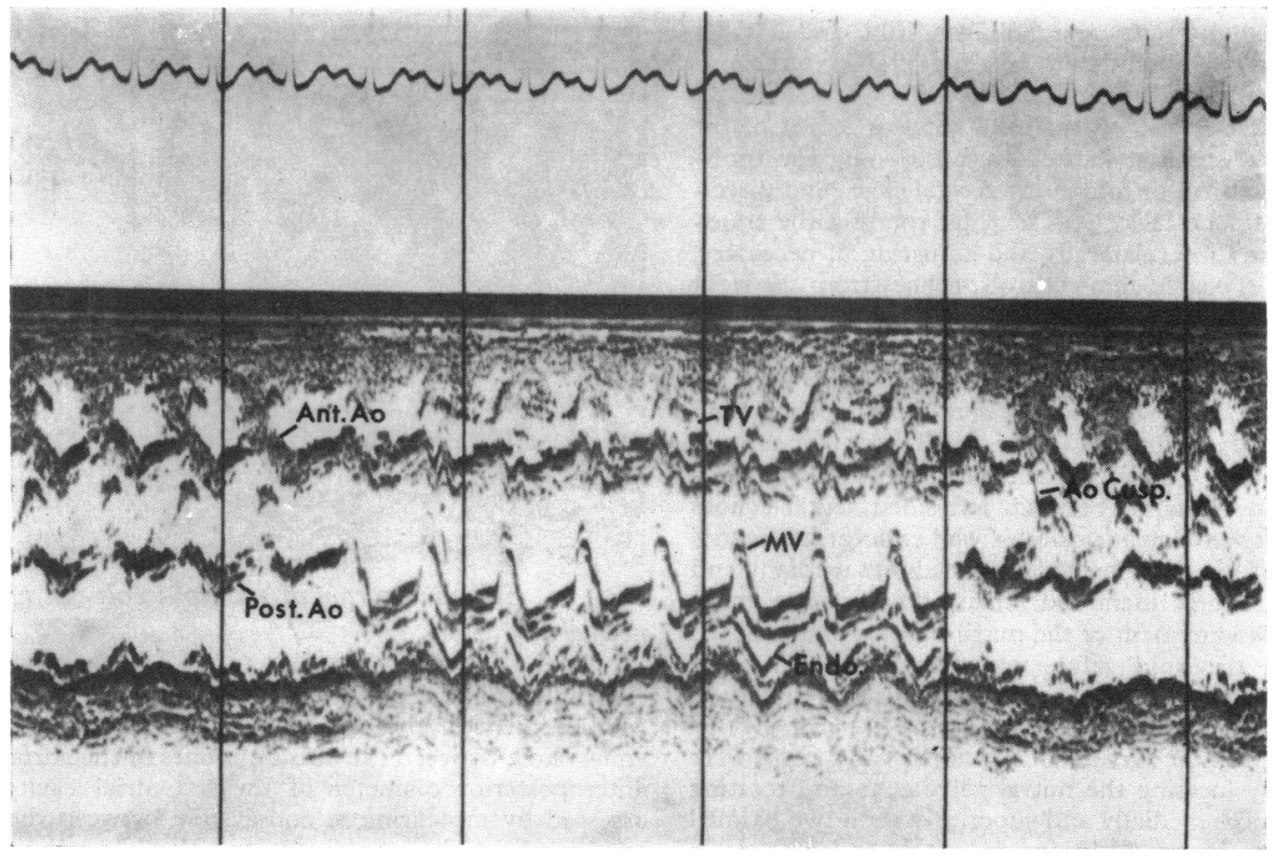

FIG. 4 Echocardiogram obtained as the transducer is moved from aorta to mitral valve and back to the aortic root. The anterior wall of the aorta is continuous with the interventricular septum and the posterior wall of the aorta merges with the anterior leaflet of the mitral valve. $T V=$ tricuspid valve, $M V=$ mitral valve. 


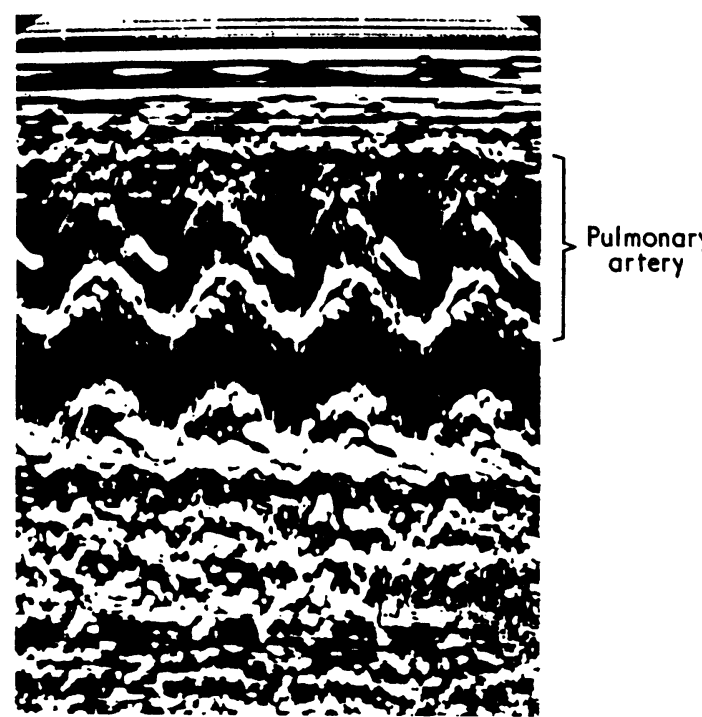

FIG. 5 Echocardiogram of pulmonary valve and pulmonary valve cusps in normal newborn.

values for the echocardiographic parameters measured in the normal newborn infants.

\section{Hypoplastic left heart syndrome}

This group included 12 infants with a number of different malformations but all had in common some degree of hypoplasia of the left ventricle (Table 3). The spectrum varied from those with an atretic
TABLE 2 Echocardiographic measurements in 50 normal newborn infants

\begin{tabular}{lll}
\hline & Range & Mean \\
\hline Age & $6 \mathrm{hr}-4 \mathrm{wk}$ & $78 \mathrm{hr}$ \\
Weight (kg) & $1 \cdot 9-4.3$ & $3 \cdot 2$ \\
Tricuspid valve excursion (mm) & $8-13$ & 11 \\
Mitral valve excursion (mm) & $6 \cdot 5-12.4$ & 10.8 \\
Aorta diameter (mm) & $8-1 \mathrm{I}$ & $10 \cdot 2$ \\
Pulmonary artery diameter (mm) & $9 \cdot 2-12 \cdot 8$ & $11 \cdot 1$ \\
Left atrial diameter (mm) & $4-10 \cdot 5$ & 6.4 \\
LV end-diastolic dimension (mm) & $12-20.4$ & 16.2 \\
RV end-diastolic dimension (mm) & $10-17.5$ & 13.8 \\
& & \\
\hline
\end{tabular}

mitral valve, a slit-like left ventricle and atretic aortic valve to those with a mildly hypoplastic left ventricle and mitral and aortic stenosis. In each case, the echocardiographic findings reflected the underlying pathology and correlated extremely accurately with the angiographic and necropsy findings. Three features characterized this group and were present in all cases (Fig. 6). Firstly, there was a large right ventricular cavity with an increased right ventricular dimension $(20-32 \mathrm{~mm})$; secondly, there was a small or absent left ventricular cavity with a decreased left ventricular dimension (o-I I mm); and thirdly, the mitral valve echo was absent or deformed. The amplitude of the excursion of the tricuspid valve in diastole tended to be at or just above the upper range of normal. Mitral valve echoes were identified in 6 of the II and the ampli-

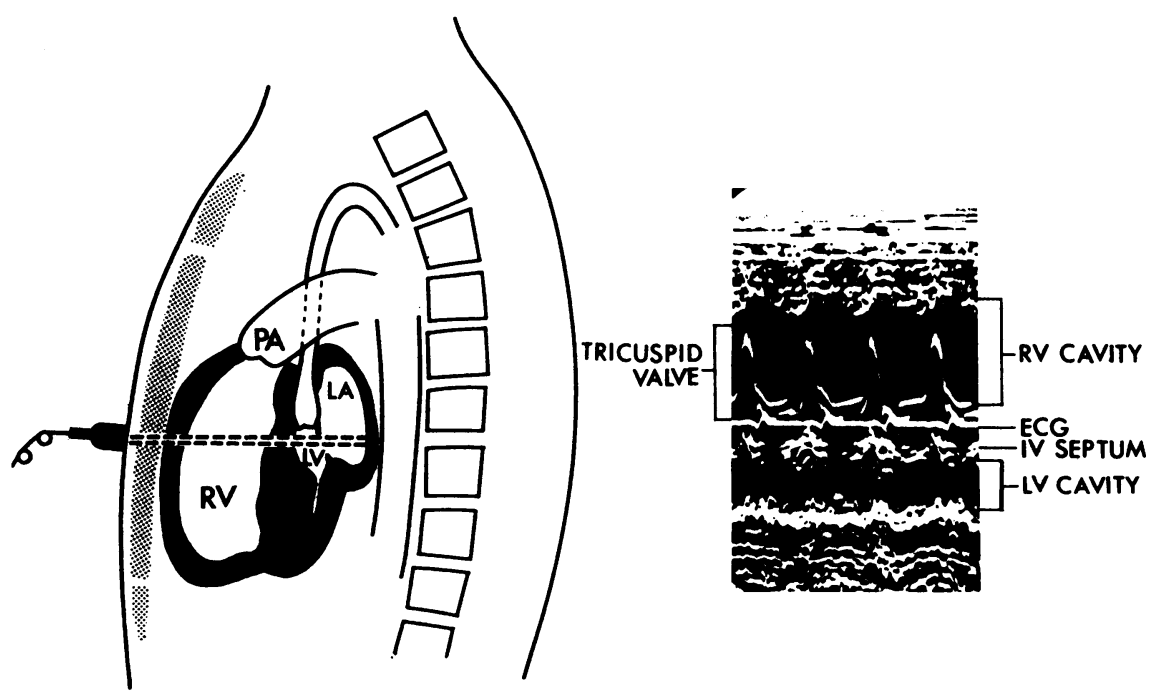

FIG. 6 Schematic diagram of hypoplastic left heart syndrome and echocardiogram demonstrating small left ventricular ( $L V)$ dimension and increased right ventricular $(R V)$ dimension and tricuspid valve with increased excursion. 
TABLE 3 Hypoplastic left heart syndrome

\begin{tabular}{|c|c|c|c|c|c|c|c|}
\hline $\begin{array}{l}\text { Case } \\
\text { No. }\end{array}$ & $\begin{array}{l}\text { Age at } \\
\text { death }\end{array}$ & $\begin{array}{l}\text { LVEDD } \\
(\boldsymbol{m m})\end{array}$ & $\begin{array}{l}\text { RVEDD } \\
(m m)\end{array}$ & $\begin{array}{l}\text { Aorta } \\
(\mathrm{mm})\end{array}$ & $\begin{array}{l}\text { Mitral valve } \\
\text { excursion }(m m)\end{array}$ & $\begin{array}{l}\text { Tricuspid valve } \\
\text { excursion (mm) }\end{array}$ & Necropsy diagnosis \\
\hline $\mathbf{I}$ & I I dy & 0 & 30 & $\circ$ & $\circ$ & 12 & $\begin{array}{l}\text { Hypoplastic aorta, mitral } \\
\text { and aortic valve atresia, } \\
\text { absent left ventricle }\end{array}$ \\
\hline 2 & $6 \mathrm{dy}$ & $\circ$ & 32 & 4 & 0 & 14 & $\begin{array}{l}\text { Hypoplastic aorta, aortic } \\
\text { and mitral valve atresia, } \\
\text { absent left ventricle }\end{array}$ \\
\hline 3 & $4 d y$ & 6 & 23 & 0 & 3 & II & $\begin{array}{l}\text { Hypoplastic aorta, aortic } \\
\text { atresia, hypoplastic mitral } \\
\text { valve, hypoplastic left } \\
\text { ventricle }\end{array}$ \\
\hline 4 & $7 \mathrm{dy}$ & 7 & 29 & 0 & 5 & 12 & $\begin{array}{l}\text { Hypoplastic aorta, aortic } \\
\text { atresia, hypoplastic mitral } \\
\text { valve, hypoplastic left } \\
\text { ventricle }\end{array}$ \\
\hline 5 & $3 \frac{1}{2} \mathrm{wk}$ & 9 & 22 & 6 & 6 & II & $\begin{array}{c}\text { Hypoplastic aorta, severe } \\
\text { aortic stenosis, hypo- } \\
\text { plastic mitral valve, } \\
\text { hypoplastic left ventricle }\end{array}$ \\
\hline 6 & I dy & $\circ$ & $3 I$ & 6 & $\circ$ & 15 & $\begin{array}{l}\text { Hypoplastic aorta, aortic } \\
\text { and mitral valve atresia, } \\
\text { absent left ventricle }\end{array}$ \\
\hline 7 & $3 \mathrm{dy}$ & o & 28 & 0 & $\circ$ & 12 & $\begin{array}{l}\text { Hypoplastic aorta, mitral } \\
\text { and aortic valve atresia, } \\
\text { absent left ventricle }\end{array}$ \\
\hline 8 & $5 \mathrm{dy}$ & I I & 21 & 6 & 8 & I0 & $\begin{array}{l}\text { Hypoplastic aorta, mildly } \\
\text { hypoplastic left ventricle, } \\
\text { aortic and mitral stenosis }\end{array}$ \\
\hline 9 & $2 \mathrm{dy}$ & 8 & 27 & 7 & 3 & 13 & $\begin{array}{l}\text { Hypoplastic aorta, aortic } \\
\text { stenosis, hypoplastic } \\
\text { mitral valve, hypoplastic } \\
\text { left ventricle }\end{array}$ \\
\hline IO & $4 d y$ & 10 & 20 & 0 & 7 & 14 & No necropsy \\
\hline II & $3 \mathrm{dy}$ & 3 & 21 & 0 & o & 12 & $\begin{array}{ccr}\text { Hypoplastic } & \text { aorta, mitral } \\
\text { stenosis } & \text { and } & \text { aortic } \\
\text { atresia, } & \text { slit-like } & \text { left } \\
\text { ventricle } & & \end{array}$ \\
\hline 12 & $2 \mathrm{dy}$ & 4 & $2 \mathrm{I}$ & 0 & o & 13 & No necropsy \\
\hline
\end{tabular}

Abbreviations: LVEDD = Left ventricular end-diastolic dimension; RVEDD = Right ventricular end-diastolic dimension.

tude of mitral valve movement reflected the degree of hypoplasia of the mitral valve (Table 3 ). Aortic root echoes were found in 5 infants. The anteroposterior diameter of the aortic root in these cases ranged from 4 to $7 \mathrm{~mm}$, compared to the normal of 6 to $13 \mathrm{~mm}$.

No false positive diagnosis was made in any infant in this group. A single false negative diagnosis was made of an echogram which in retrospect clearly showed mild left ventricular hypoplasia in an infant who also had severe aortic and mitral stenosis.

\section{Pulmonary atresia with intact ventricular septum and tricuspid atresia: hypoplastic right heart syndrome}

The findings in the 5 neonates with pulmonary atresia and an intact ventricular septum and in the
2 with tricuspid atresia were in striking contrast to those seen in the hypoplastic left heart syndrome. In all cases, the left ventricular dimension was increased or at the upper limit of normal (I 7 to $30 \mathrm{~mm}$ ) with an amplitude of excursion of the anterior mitral valve leaflet which was at the upper limit of normal (Io to $15 \mathrm{~mm}$ ) (Fig. 7). In 2 cases, no right ventricular cavity could be identified and in the remaining 5 , the right ventricular dimension was much reduced ( 2 to $6 \mathrm{~mm}$ ) compared with normal. Normal mitral valve and aortic valve continuity was present in all cases. There were no diagnostic features that distinguished between pulmonary atresia and tricuspid atresia, except for the presence of a very hypoplastic and deformed tricuspid valve echo in 2 of the infants with pulmonary atresia and an intact ventricular septum. 


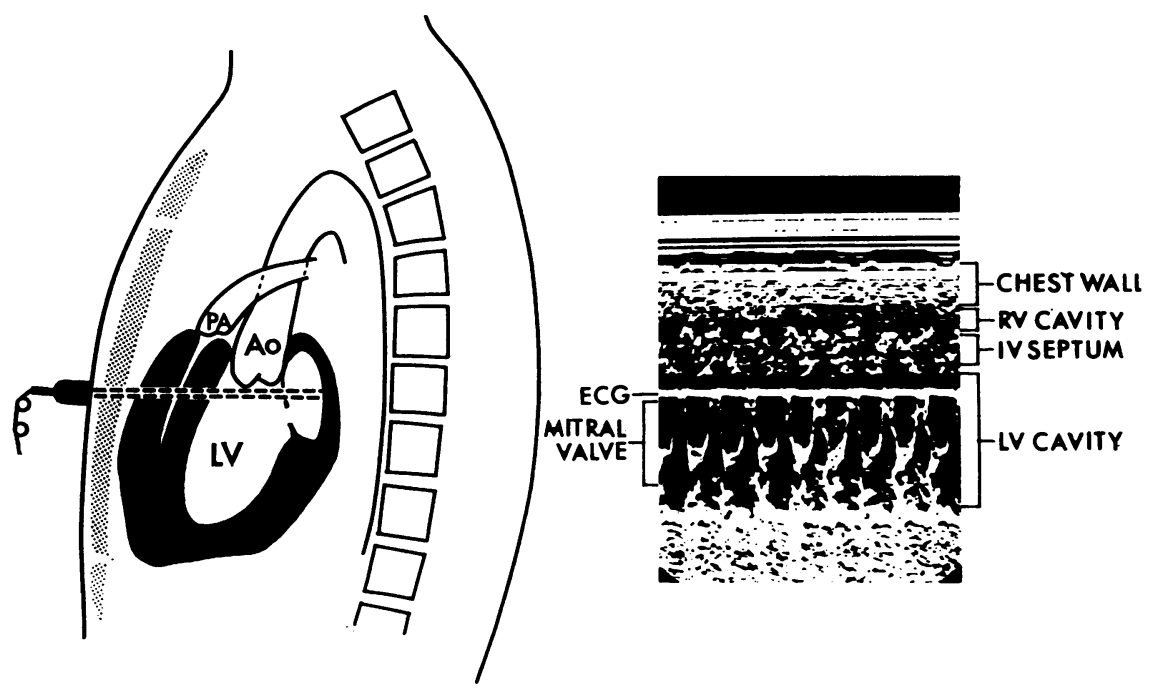

FIG. 7 Schematic diagram of tricuspid atresia with echocardiogram showing pronounced diminution in the right ventricular $(R V)$ dimension and readily defined mitral valve motion.

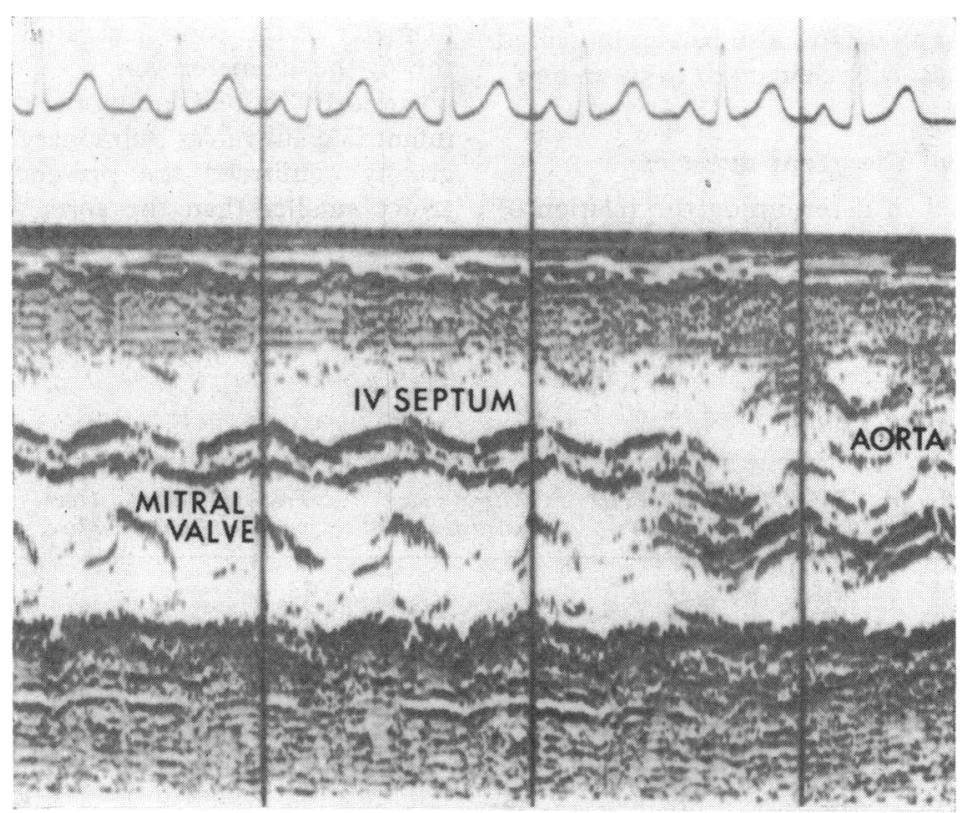

FIG. 8 Echocardiogram in tetralogy of Fallot demonstrating discontinuity between the anterior wall of the aorta and interventricular (IV) septum with resulting 'overriding' of the aorta. 
TABLE 4 Pulmonary atresia with intact ventricular septum and tricuspid atresia

\begin{tabular}{|c|c|c|c|c|c|}
\hline $\begin{array}{l}\text { Case } \\
\text { No. }\end{array}$ & Age & $\begin{array}{l}\text { LVEDD } \\
(\mathrm{mm})\end{array}$ & $\begin{array}{l}\text { RVEDD } \\
(\mathrm{mm})\end{array}$ & $\begin{array}{l}\text { Mitral valve } \\
\text { excursion } \\
(\mathrm{mm})\end{array}$ & $\begin{array}{l}\text { Tricuspid } \\
\text { valve } \\
\text { excursion } \\
(\mathrm{mm})\end{array}$ \\
\hline
\end{tabular}

\begin{tabular}{|c|c|c|c|c|}
\hline \multicolumn{5}{|c|}{ Pulmonary atresia } \\
\hline I & $8 \mathrm{dy} 20$ & 5 & 12 & 2 \\
\hline 2 & 7 dy 18 & 6 & II & 2 \\
\hline 3 & I5 dy 30 & 0 & 15 & 0 \\
\hline 4 & 2 dy 17 & 2 & I0 & o \\
\hline 5 & 6 dy 19 & ० & 12 & 0 \\
\hline \multicolumn{5}{|c|}{ Tricuspid atresia } \\
\hline 6 & 5 dy 20 & 3 & 13 & 0 \\
\hline 7 & 3 dy 18 & 2 & 14 & o \\
\hline
\end{tabular}

Abbreviations: LVEDD = Left ventricular end-diastolic dimension; RVEDD = Right ventricular end-diastolic dimension.

\section{Tetralogy of Fallot}

There were 9 infants with a proven diagnosis of tetralogy of Fallot. Using only polaroid films, a confident diagnosis was made in 2 out of 4 cases. When the strip chart recorder was used a diagnosis was made in the next 5 cases without error. Echocardiographic demonstration of discontinuity between the anterior wall of the aorta and the interventricular septum was the principal diagnostic feature (Fig. 8), but all 9 cases also had an increased aortic root anteroposterior diameter ( 14 to $22 \mathrm{~mm}$ ).

\section{D-transposition of the great arteries}

The technique used in determining the relation of the great vessels was as described by Gramiak et al. (1973). Normally, at the left sternal edge a medially directed transducer beam locates the aorta posteri- orly or deep to the anterior chest wall, whereas with the transducer directed laterally, to the left and slightly superiorly, the pulmonary artery is detected lying anteriorly (Fig. 9). The reverse findings are found in D-transposition of the great arteries. A medially directed beam locates the aorta as lying anteriorly, immediately beneath the anterior chest wall, and a lateral and leftward-directed beam finds the pulmonary artery posterior to the aorta (Fig. IO). This method of determining the spatial relation of the great vessels is greatly helped by a continuous recording technique such as a strip chart facility.

Ten cases of D-transposition were studied, but in 4 of these recordings were obtained only on polaroid film and in only I of these 4 did we feel confident about the abnormal spatial relations. However, with the strip chart facility a confident and correct prediction of the great vessel relation was made in 5 out of 6 cases and in the sixth case opinion was reserved, since a satisfactory recording of the anterior vessel could not be obtained. In 3 cases the aorta was identified as lying directly above the pulmonary artery (Fig. II). In 2 of these 3 cases, by edging the transducer slightly more superiorly as well as medially, the posterior vessel disappeared from view and stronger signals were obtained from the anteriorly located aorta. Because of lack of resolution between anterior chest wall echoes and the anterior wall of the superficially located aorta, it was only possible to measure the anteroposterior diameter of the aorta accurately in 6 cases. In 5 of the 6 , the diameter was 2 to $5 \mathrm{~mm}$ less than the posteriorly located pulmonary artery. The sixth infant had subvalvar pulmonary stenosis and angiography confirmed the presence of a pulmonary artery smaller than the aorta. The right and left ventricular dimensions were within the normal range as were the measurements of the amplitude of mitral and tricuspid valve movement.

TABLE 5 Tetralogy of Fallot

\begin{tabular}{|c|c|c|c|c|c|c|c|c|}
\hline $\begin{array}{l}\text { Case } \\
\text { No. }\end{array}$ & Age & $\begin{array}{l}\text { Aorta } \\
(\mathrm{mm})\end{array}$ & $\begin{array}{l}\text { RVEDD } \\
(\mathrm{mm})\end{array}$ & $\begin{array}{l}\text { LVEDD } \\
(\mathrm{mm})\end{array}$ & $\begin{array}{l}\text { Mitral valve } \\
\text { excursion }(\mathrm{mm})\end{array}$ & $\begin{array}{l}\text { Tricuspid valve } \\
\text { excursion }(\mathrm{mm})\end{array}$ & $\begin{array}{l}\text { Over- } \\
\text { riding }\end{array}$ & Comment \\
\hline $\mathbf{I}$ & $8 \mathrm{dy}$ & 14 & 14 & 12 & 10 & 12 & + & Polaroid film \\
\hline 2 & ro dy & 18 & 16 & 18 & 13 & 12 & NI & Polaroid film \\
\hline 3 & I $7 \mathrm{dy}$ & $2 \mathbf{I}$ & 17 & 17 & 14 & 13 & NI & Polaroid film \\
\hline 4 & $12 \mathrm{dy}$ & 19 & 14 & 15 & 13 & 12 & + & Polaroid film \\
\hline 5 & 4 wk & 20 & 16 & 14 & II & 9 & + & Strip chart recording \\
\hline 6 & $3 \frac{1}{2} \mathrm{wk}$ & 16 & 12 & 13 & Io & 9 & + & Strip chart recording \\
\hline 7 & 3 wk & 22 & 18 & 20 & 15 & II & + & Strip chart recording \\
\hline 8 & I4 dy & 20 & 14 & 15 & I4 & 13 & + & Strip chart recording \\
\hline 9 & $7 \mathrm{dy}$ & 15 & 10 & 18 & 12 & 9 & + & Strip chart recording \\
\hline
\end{tabular}

Abbreviations: RVEDD = Right ventricular end-diastolic dimension; LVEDD = Left ventricular end-diastolic dimension; NI $=$ Not identified. 


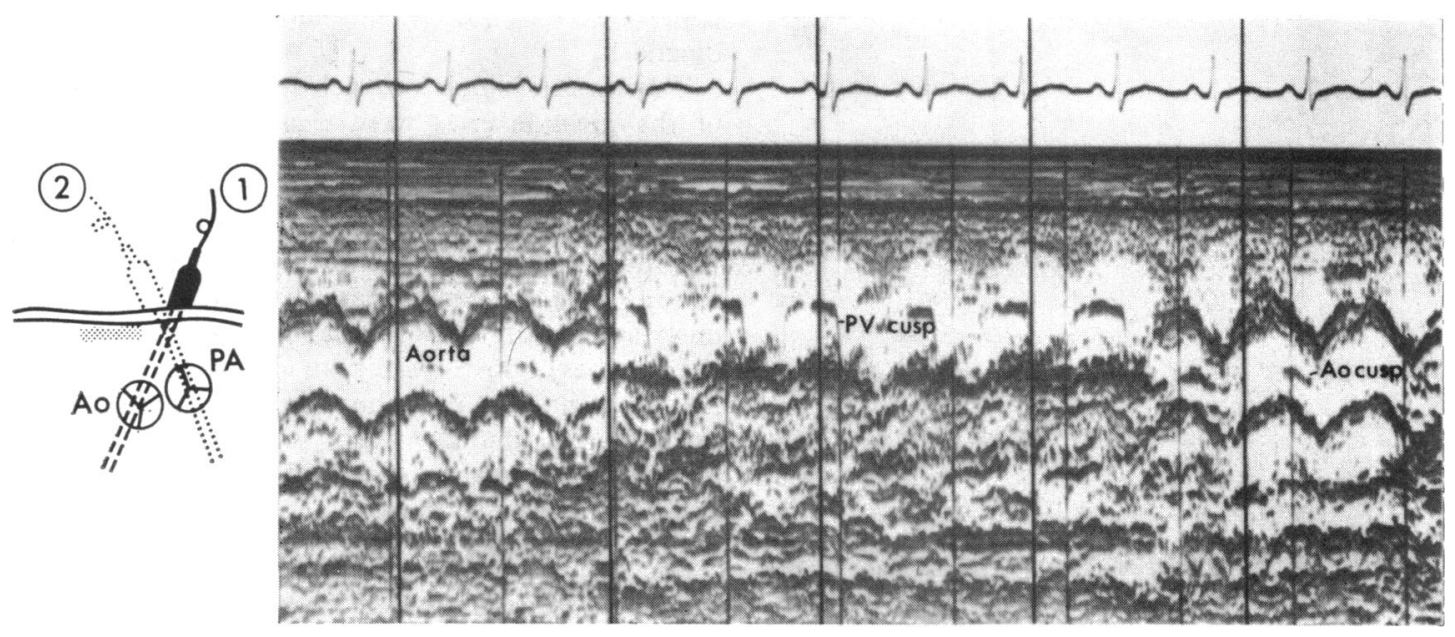

FIG. 9 Diagrammatic representation and echocardiogram of the normal spatial relations of the great vessels. The transducer is located at the left sternal edge and viewed from below. Normally, as here, a medially directed transducer beam (I) locates the aorta posteriorly or deep to the anterior chest wall, whereas with the rotation of the transducer laterally, to the left, and slightly superiorly (2), the pulmonary artery is detected as lying anteriorly.

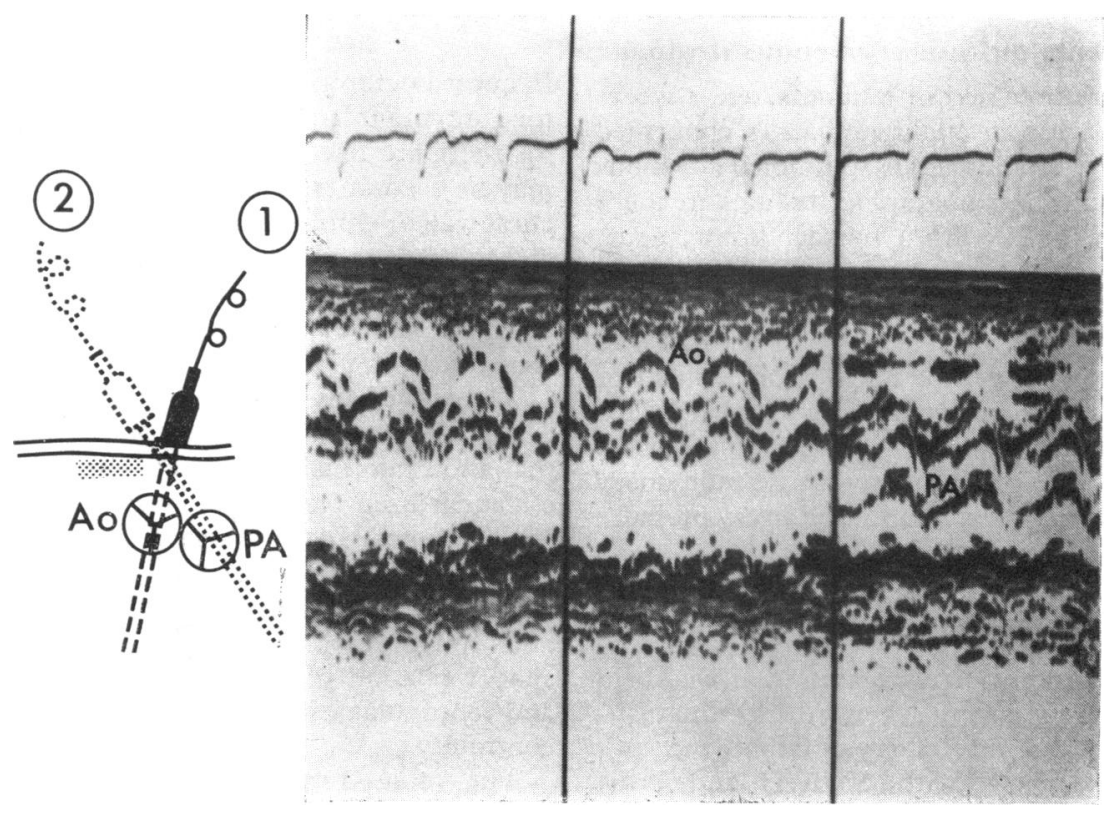

FIG. IO In D-transposition of the great vessels a medially directed transducer beam (I) locates the aorta lying anteriorly and a laterally directed transducer beam (2) finds the pulmonary posteriorly and deep to the anterior chest wall - a reversal of the normal spatial relations. 


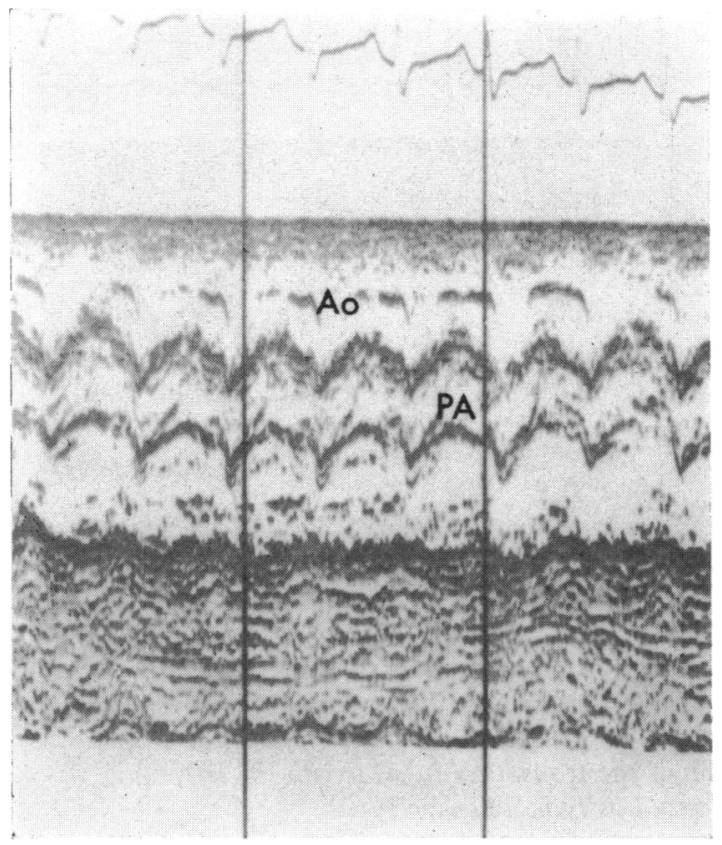

FIG. II Echocardiogram in D-transposition of the great arteries showing the aorta lying directly anterior to the pulmonary.

\section{Total anomalous pulmonary venous drainage}

Recordings were obtained in 2 infants, age 2 weeks and $3 \frac{1}{2}$ weeks, with an angiographically confirmed diagnosis of total anomalous pulmonary venous drainage. The echocardiographic findings in the 2 week-old infant were within normal limits, apart from a right ventricular dimension that was slightly increased at $18 \mathrm{~mm}$. The $3 \frac{1}{2}$-week-old infant had an increased right ventricular dimension of $20 \mathrm{~mm}$ and also had pronounced paradoxical movement of the interventricular septum (Fig. I2 a and b). This infant had a large pulmonary blood flow with a $\mathrm{Qp}: \mathrm{Qs}$ ratio of 3.5:I and only moderate pulmonary hypertension with a mean pulmonary artery pressure of $30 \mathrm{mmHg}$.

\section{Miscellaneous}

The echocardiographic findings in a 4-week-old infant with truncus arteriosus were indistinguishable from those seen in tetralogy of Fallot (Fig. 13). This infant presented with cyanosis and heart failure, and radiologically had increased pulmonary blood flow. The clinical diagnosis was truncus arteriosus or D-transposition of the great arteries with a ventricular septal defect. Echocardiography easily excluded the latter and confirmed the first diagnosis.

Two cases of single ventricle with $\mathrm{D}$-transposition of the great arteries were examined early in the series. In neither case could an adequate assessment be obtained of the spatial relation of the great vessels. In both cases, however, no interventricular septum was identified. In one of these cases there appeared to be a single atrioventricular valve moving conspicuously anterior in diastole (Fig. I4).

In 2 cases of dextrocardia, an inadequate examination was obtained in I, but in the other the echocardiographic findings again suggested absence of the interventricular septum and this was confirmed at cardiac catheterization.

\section{Cyanotic infants with no organic heart disease}

There were 6 infants who presented with cyanosis and initially were thought to have cyanotic congenital heart disease. All had normal echocardiograms. Of these 6 infants, 3 subsequently were catheterized and were found only to have a high pulmonary vascular resistance with right-to-left shunting at ductal level and in 2, also via a patent foramen ovale. In the remaining 3 cases the clinical course suggested that the cyanosis had been due to respiratory causes.

\section{Discussion}

Echocardiography is a particularly suitable method for studying infants and children with heart disease, for there are few of the technical difficulties which may be encountered in adults who may have a thick chest wall or emphysema. Recording of the tricuspid and pulmonary valves is much easier in the newborn infant due to the absence of calcification in the sternum and the proximity of the valves to the transducer.

The aim of any echocardiographic study must be to offer as much information as possible about normal and abnormal cardiac anatomy. By employing a standardized technique, as emphasized by others (Feigenbaum, 1972; Solinger et al., 1973), it was possible in this study to determine the presence or absence of the interventricular septum, the number and function of the atrioventricular valves, the spatial relation of the great vessels, chamber size and ventricular septal-aortic, as well as mitral-aortic, continuity.

The values for a number of echocardiographic parameters in the normal neonate have been reported previously (Solinger et al., I973; Hagan and Deeley, 1973). The measurements in our group of normal newborns are in agreement with these larger series. 


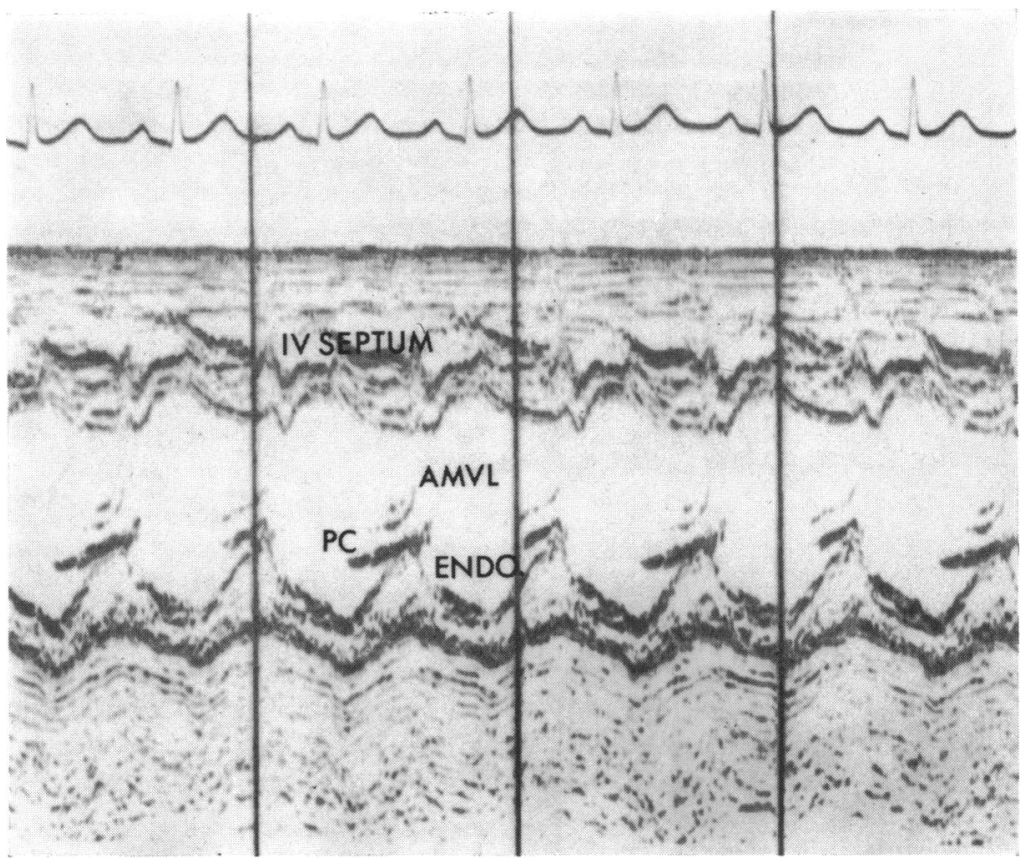

$a$

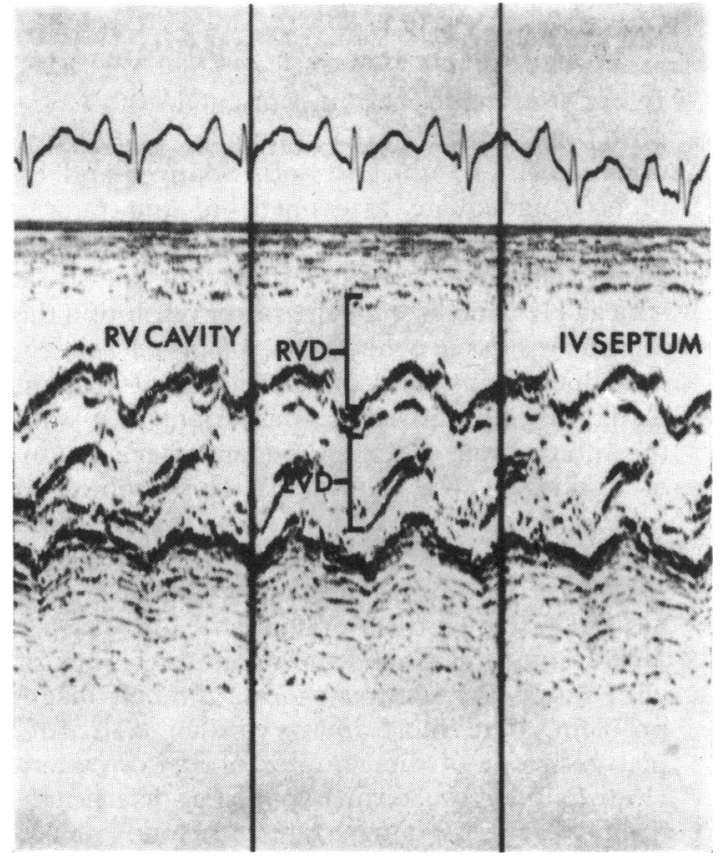

F IG. I2 a) Echocardiogram showing normal movement of the interventricular (IV) septum. The interventricular septal and posterior left ventricular wall move towards each other in systole. $A M V L=$ anterior mitral valve leaflet; $P C=$ posterior chordae; Endo=endocardium. b) Echocardiogram from a $3 \frac{1}{2}$-week-old infant with total anomalous pulmonary venous drainage. The interventricular septum moves paradoxically in systole, i.e. moves anteriorly not posteriorly. The right ventricular dimension (RVD) is greater than the left ventricular dimension (LVD). 


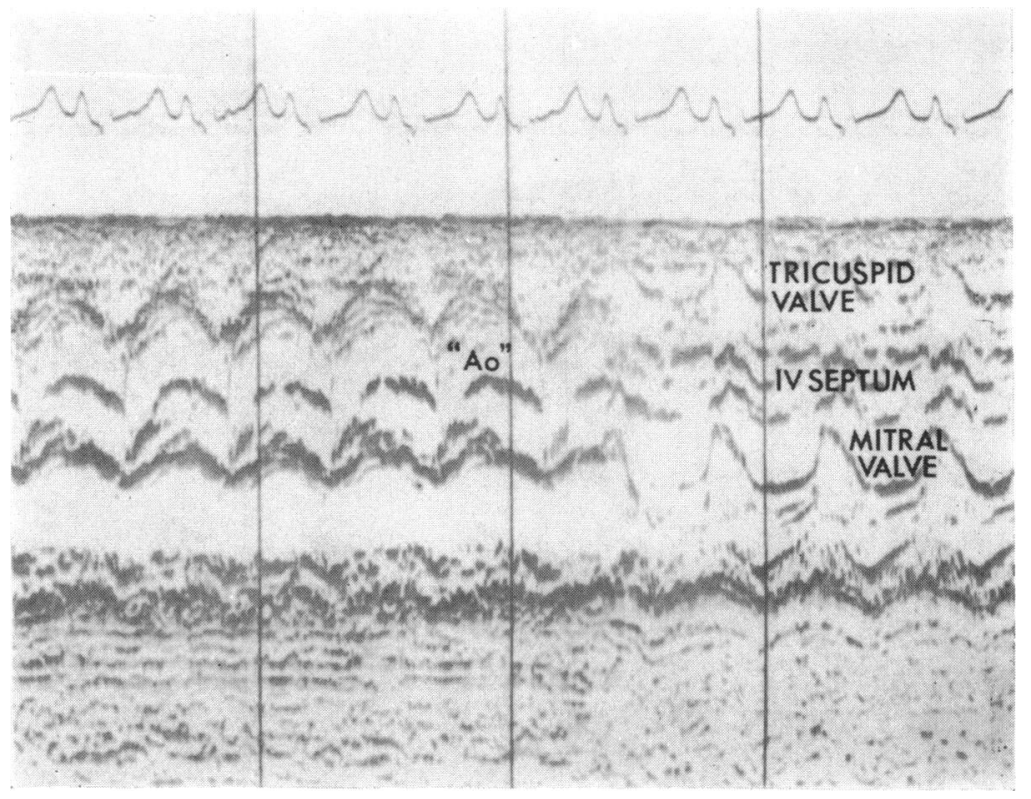

FIG. I3 Echocardiogram showing overriding of the interventricular septum by a common trunk ('Ao') in truncus arteriosus.

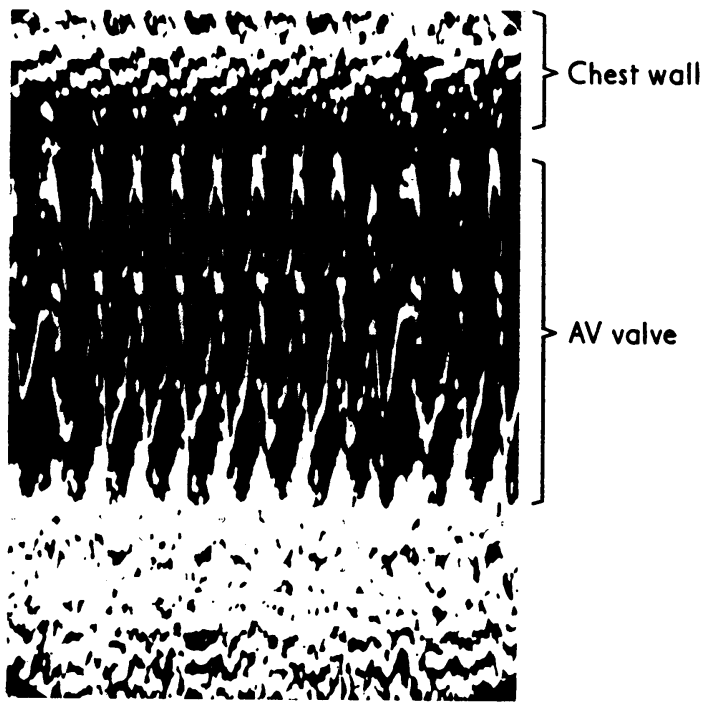

FIG. I4 Echocardiogram from an infant with $a$ single ventricle. There appears to be a single $A V$ valve with much increased excursion moving abnormally anteriorly towards the chest wall.
In our study, however, measurements of the anteroposterior diameter of the pulmonary artery were not obtained in all subjects. Both Solinger and Hagan reported adequate assessment of the pulmonary artery in the infants whom they studied. Both these groups employed a higher frequency transducer of $5 \mathrm{mega} \mathrm{Hz}$ which results in greater resolution though diminished tissue penetration. Using a 2.25 mega Hz transducer, we found difficulty in some patients in distinguishing between the anterior chest wall and the anterior wall of the pulmonary artery due to lack of resolution. We believe that this problem could have been reduced by employing a higher frequency transducer in these cases. Since completion of this study, further experience with such a transducer has strengthened this opinion.

The infant who presents in the first week of life with shock-like features poses a difficult diagnostic problem. The most likely cardiac cause of this picture is one of the complex of malformations included under the term hypoplastic left heart syndrome (Lambert, Tingelstad, and Hohn, 1966). The clinical features, however, can be mimicked by sepsis and other non-cardiac causes. The findings 
in the present report suggest that echocardiography is an extremely reliable and accurate method of distinguishing between the hypoplastic left heart syndromes and non-cardiac causes that result in a similar clinical picture. We would also agree with Meyer and Kaplan (1972) that cardiac catheterization can be avoided if the echocardiogram supports a diagnosis of the hypoplastic left heart syndrome for no false positive diagnosis was made in 12 cases.

The echocardiographic appearances in pulmonary atresia with intact ventricular septum and tricuspid atresia are also, in our experience, diagnostic. Chesler et al. (1971) suggested that difficulties might arise in differentiating between these conditions and single ventricle. In tricuspid atresia and pulmonary atresia with an intact ventricular septum, however, a small right ventricular cavity is usually identified and normal mitral aortic continuity is maintained. Some cases of pulmonary atresia with an intact ventricular septum may be difficult to distinguish clinically, radiologically, and electrocardiographically from tetralogy of Fallot. Echocardiography can rapidly and easily differentiate between the two conditions by demonstrating not only overriding of the interventricular septum by the aorta in tetralogy of Fallot, but also the presence of a normal size right ventricular cavity in this condition compared with pulmonary atresia with an intact ventricular septum. Overriding of the interventricular septum by a common trunk is also found in truncus arteriosus, but the clinical findings in this condition usually suggest a large left-to-right shunt and are not confused with tetralogy of Fallot.

Complete transposition of the great arteries is the most common congenital heart lesion in which cyanosis is present from birth (Lambert et al., 1966). The echocardiographic diagnosis of D-transposition of the great arteries in this study depended principally on the demonstration of reversal of the normal anteroposterior relation of the great vessels. A continuous recording method such as a strip chart facility helps considerably, for it allows repeated sweeps of the transducer to be made between the aorta and the pulmonary artery. In the newborn infant, small adjustments in the transducer position may alter the direction of the ultrasound beam, and this is much easier to recognize when a continuous recording technique is employed than with polaroid films alone. The diagnosis of D-transposition of the great arteries may also be suspected if an anterior vessel is identified as lying directly above a posterior vessel which has a large anteroposterior diameter (Solinger et al., 1973). The pulmonary artery in the neonate with normally related great vessels usually has a larger anteroposterior diameter than the aorta. In 5 of the 6 cases of D-transposition in our series, in whom measurement of the anteroposterior diameter of the great vessels was possible, the pulmonary artery was 2 to $5 \mathrm{~mm}$ larger than the aorta in diameter. The sixth case, with a small pulmonary artery, had subvalvar pulmonary stenosis. The pulmonary artery, then, whether it is anteriorly or posteriorly situated, is usually, though not invariably a larger vessel than the aorta in the neonate.

Complete transposition of the great arteries is not only the most common cardiac cause of cyanosis in the newborn, but in our experience also the most difficult to distinguish from non-cardiac causes of cyanosis. The distinction from those infants who have persistence of the fetal circulation may be particularly difficult in the first few days of life. Persistent fetal circulation, which is associated with abnormal right-to-left shunting (via a persistent ductus arteriosus or patent foramen ovale), secondary to a rise in the pulmonary vascular resistance, may occur in newborn infants with a variety of disease processes, such as hyperviscosity, atypical respiratory distress syndrome, or hypoglycaemia (Robertson, Hallidie Smith, and Davis, 1967; Gersony, 1973). Echocardiography seems to be a particularly useful noninvasive technique in screening these infants. A normal echocardiogram in such cases should suggest the possibility that non-cardiac factors are responsible for the disturbed haemodynamics which result in cyanosis. Six infants in this study were in this category. All had normal echocardiograms.

It has been claimed that total anomalous pulmonary venous drainage has characteristic echocardiographic findings which consist of a small left ventricular dimension and a left atrial dimension at the lower limit of normal (Meyer and Kaplan, 1973). Both of the cases in our study had normal left ventricular and left atrial dimensions. In both cases the right ventricular dimension was increased, and in one the diagnosis was suspected because of paradoxical motion of the interventricular septum due to right ventricular volume overloading. It is possible, however, that in the majority of cases in the newborn period the interventricular septum moves normally because of the presence of right ventricular hypertension. It is important to emphasize that the echocardiographic appearances in total anomalous pulmonary venous drainage can be almost within normal limits in the newborn.

In conclusion, our experience suggests that echocardiography is not only rapid and non-invasive, but also in most cases an extremely accurate method of diagnosing congenital heart disease in the neonate. Even though it may not always represent the final diagnostic step, it adds considerably to the evaluation before cardiac catheterization and is valuable in planning the definitive catheter investigation. 


\section{References}

Chesler, E., Joffe, H. S., Beck, W., and Schire, V. (197I). Echocardiography in the diagnosis of congenital heart disease. Pediatric Clinics of North America, 18, I163.

Feigenbaum, H. (1972). Clinical applications of echocardiography. Progress in Cardiovascular Diseases, 14, 531.

Gersony, W. M. (1973). Persistence of the fetal circulation. Fournal of Pediatrics, 82, 1103.

Gramiak, R., Chung, K. J., Nanda, N., and Manning, J. (1973). Echocardiographic diagnosis of transposition of the great vessels. Radiology, 106, 187.

Hagan, A. D., and Deeley, W. J. (1973). Echocardiographic criteria for normal newborn infants. American fournal of Cardiology, 31, 137.

Lambert, E. C., Tingelstad, J. B., and Hohn, A. R. (1966). Diagnosis and management of congenital heart disease in the first week of life. Pediatric Clinics of North America, 13, 943 .
Lundström, N. R., and Edler, I. (I97I). Ultrasoundcardiography in infants and children. Acta Paediatrica Scandinavia, 60, 117 .

Meyer, R. A., and Kaplan, S. (1972). Echocardiography in the diagnosis of hypoplasia of the left or right ventricles in the neonate. Circulation, 46, 55.

Meyer, R. A., and Kaplan, S. (1973). Non-invasive techniques in pediatric cardiovascular disease. Progress in Cardiovascular Diseases, 15, 341.

Robertson, N. R. C., Hallidie-Smith, K. A., and Davis, J. A. (1967). Severe respiratory distress syndrome mimicking cyanotic heart-disease in term babies. Lancet, $2,1108$.

Solinger, R., Elbl, F., and Minhas, K. (1973). Echocardiography in the normal neonate. Circulation, 47, 108.

Requests for reprints to Dr. Michael J. Godman, Royal Hospital for Sick Children, Sciennes Road, Edinburgh EH9 ILF, Scotland. 